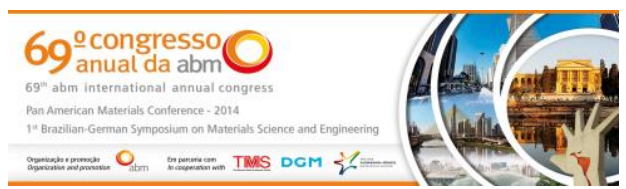

Tema: Soldagem

\title{
ESTUDO COMPARATIVO DA ZONA TERMICAMENTE AFETADA DE JUNTAS SOLDADAS OBTIDAS PELOS PROCESSOS DE SOLDAGEM FCAW E SMAW*
}

\author{
Diniz Ramos de Lima Júnior ${ }^{1}$ \\ Bruna Nayara Pereira da Silva² \\ Magda Rosângela Santos Vieira ${ }^{3}$ \\ Oscar Olimpio de Araujo Filho ${ }^{4}$ \\ Severino Leopoldino Urtiga Filho ${ }^{4}$
}

\section{Resumo}

Dentro das refinarias os tanques de armazenamento desempenham um papel fundamental, pois armazenam matéria prima para abastecimento das unidades, produtos intermediários entre os processos e produtos finais para distribuição. $O$ presente trabalho apresenta de modo comparativo as características mecânicas e microestruturais da zona termicamente afetada de juntas soldadas formadas pelos processos de soldagem com Arame Tubular (FCAW) e Eletrodo Revestido (SMAW) aplicados na fabricação e reparo de tanques de armazenamento utilizados na indústria de petróleo. Os procedimentos de soldagem para cada junta soldada seguiram EPS (Especificação do Procedimento de Soldagem) utilizada por uma empresa que fabrica e repara tanques de armazenamento para indústrias de petróleo. O metal de base utilizado foi o aço estrutural de classificação ASTM A-36 em geometria plana e com chanfro tipo K. A solda foi multipasses de topo na posição horizontal (2G). Para realização deste estudo foram realizados quatro tipos de ensaios destrutivos: tração, microdureza Vickers, impacto Charpy e metalográfia. Os resultados indicaram a importância da seleção do processo de soldagem em termos de produção e formação da junta soldada e uma heterogeneidade devido as diferentes microestruturas presentes nas zonas termicamente afetadas que demostraram grande influência no perfil de microdureza.

Palavras-chave: Características mecânicas e microestruturais; Zona termicamente afetada; Aço ASTM-A36; FCAW; SMAW.

\section{COMPARATIVE STUDY ABOUT HEAT AFFECTED ZONE OF WELDED JOINTS OBTAINED BY SMAW AND FCAW WELDING PROCESSES}

\begin{abstract}
The storage tanks play a key role inside of refineries, because store raw material to supply the units, intermediate products between the processes and the final products for distribution. This paper compares the mechanical characteristics and microstructure of heat affected zone in welded joints formed by Shielded Metal Arc Welding (SMAW) and Flux-cored arc welding (FCAW) processes applied in the manufacture and repair of storage tanks used in the petroleum industry. The welding procedures for each welded joint followed WPS (Welding Procedure Specification) used by a company that manufactures and repairs storage tanks for petroleum industry. The base metal used ASTM A-36 steel in plane geometry and chamfer type K. The kind of weld was top multipasses horizontally (2G). For realized this study were carried out four types of destructive tests: tensile test, Vickers microhardness, Charpy impact and metallographic analysis. The results indicate the importance of the welding process, regarding production and formation of the welded joint, and a heterogeneity due the different microstructures present in the heat affected zone areas that demonstrated great influence the profile of microhardness.

Keywords: Mechanical characteristics and microstructural; Heat affected zone; ASTM-A36; FCAW; SMAW.

Engenheiro Mecânico, mestre, doutorando, professor IFPE, Caruaru, PE, Brasil. Engenheira Mecânica, mestre, doutoranda, PPGEM, UFPE, Recife, PE, Brasil.

Bacharel em Química, doutora, professora, DEMEC, UFPE, Recife, PE, Brasil.

Engenheiro Mecânico, doutor, professor, DEMEC, UFPE, Recife, PE, Brasil.
\end{abstract}

\footnotetext{
* Contribuição técnica ao 69ำ Congresso Anual da ABM - Internacional e ao 14ํㅡㄹ ENEMET - Encontro Nacional de Estudantes de Engenharia Metalúrgica, de Materiais e de Minas, 21 a 25 de julho de 2014, São Paulo, SP, Brasil.
} 
1 INTRODUÇÃO

Com o desenvolvimento industrial, a utilização de instalações metálicas enterradas ou submersas, tais como oleodutos, gasodutos, adutoras, navios, plataformas de petróleo, tanques de armazenamento, dentre outras, tem sido cada vez mais frequente.

O aço ASTM A-36 é um aço estrutural muito utilizado em diversos setores destas indústrias, sendo notório o destaque na fabricação de tanques de armazenamento de petróleo e seus derivados.

Dentro das refinarias estes tanques armazenam matéria prima para abastecimento das unidades, produto intermediário que é o produto final de uma unidade e matéria prima de outra, além de produto final que está pronto para distribuição.

Em todos estes segmentos percebemos uma intensa busca pela melhoria na qualidade das juntas soldadas na fabricação destas estruturas para evitar o risco de acidentes como, por exemplo, uma ruptura, já que a maioria destes tanques armazenam produtos que são prejudiciais ao meio ambiente e saúde das pessoas que ali trabalham.

Os processos de soldagem com Arame tubular (FCAW) e eletrodo revestido (SMAW) são bastante utilizados nestes setores devido à ampla aplicação em termos de espessuras e materiais utilizados.

O presente trabalho analisou a zona termicamente afetada de uma junta soldada obtida por processo de soldagem com arame tubular e outra junta soldada com processo de soldagem com eletrodo de revestido, ambos utilizados no reparo de tanques de armazenamento de petróleo tendo como objetivo avaliar as características microestruturais e mecânicas destas juntas soldadas.

\section{MATERIAIS E MÉTODOS}

Para confecção das duas juntas soldadas foram utilizadas chapas de aço de classificação ASTM A-36 como metal de base e os processos de soldagem arame tubular (FCAW) e eletrodo revestido (SMAW). Em uma das juntas soldadas foi utilizado como consumível o arame tubular de classificação AWS E71T-1 com diâmetro de 1,2 milímetros e para proteção da poça de fusão $100 \%$ de $\mathrm{CO}_{2} \mathrm{como}$ gás de proteção. $\mathrm{Na}$ outra junta soldada foi utilizado o eletrodo revestido de classificação E7018. [1-3]

A Tabela 1 apresenta a composição química do metal de base e dos metais depositados utilizados para obtenção das juntas soldadas obtidos através do catálogo do fabricante.

Tabela 1- Composição química em \% do aço ASTM A-36 e metal depositado fornecidos pelo fabricante.

\begin{tabular}{cccccc}
\hline & $\%$ C (máx.) & $\%$ Mn & $\% \mathbf{P}($ máx.) & $\% \mathbf{S}$ & $\% \mathbf{S i}$ \\
\hline ASTM A-36 & 0,25 & $0,80-1,20$ & 0,04 & 0,05 & 0,40 \\
\hline AWS E71T-1 & 0,03 & 1,40 & $<0,025$ & $<0,025$ & 0,06 \\
\hline E7018 & 0,07 & 1,30 & --- & --- & 0,50 \\
\hline
\end{tabular}

\footnotetext{
* Contribuição técnica ao 69ำ Congresso Anual da ABM - Internacional e ao 14ํㅡㄹ ENEMET - Encontro Nacional de Estudantes de Engenharia Metalúrgica, de Materiais e de Minas, 21 a 25 de julho de 2014, São Paulo, SP, Brasil.
} 


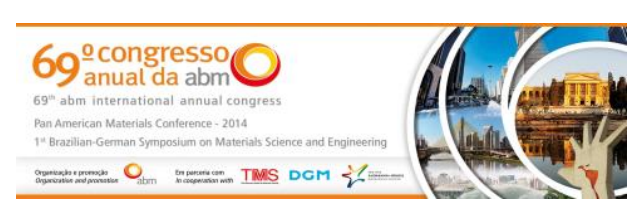

\subsection{Preparação Metalográfica}

A preparação dos corpos de prova para analise metalográfica foi iniciada com o corte das juntas soldadas na região perpendicular ao cordão de solda em uma serra de fita refrigerada. Em seguida o material cortado foi transportado para uma cortadora metalográfica para regularização das dimensões do corpo de prova. Vale ressaltar que todos os cortes foram realizados com a utilização de refrigeração. Após o procedimento de corte e regularização das dimensões dos corpos de prova foram realizados lixamentos com utilização de lixas de granulometrias na sequência de $180,220,320,400,600$ e 1200. Ao final do lixamento foi realizado polimento utilizando pastas abrasivas de alumina com granulometria e sequência de $1 \mu \mathrm{m}$ e $1 / 4$ $\mu \mathrm{m}$, seguido de ataque químico por imersão com Nital $2 \%$ para análise microestrutural da zona termicamente afetada em microscópio ótico com aumentos de 20X, 50X 100X, 200X, 500X e 1000X.

\subsection{Amostras para Ensaio de Tração}

Para confecção dos corpos de prova para realização dos ensaios de tração as juntas soldadas foram seccionadas no sentido transversal do cordão de solda utilizando serra de fita com refrigeração. Em seguida, as seções retiradas de cada junta soldada foram pré-usinadas em torno mecânico convencional para obtenção de geometria cilíndrica e logo em seguida em torno CNC (Comando Númerico Computadorizado), para obtenção das dimensões e tolerâncias especificadas na norma ASTM E8/E8M - 2011. [4]

A Figura 1 apresenta a geometria e dimensões dos corpos de prova utilizados no ensaio de tração.

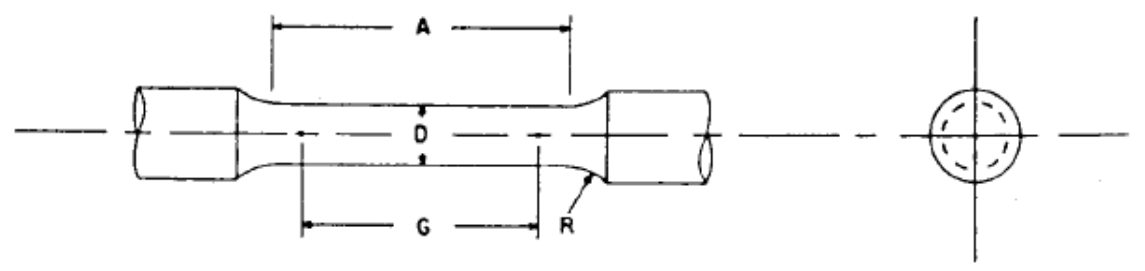

Figura 1- Geometria e dimensões dos corpos de prova segundo a Norma ASTM E8/E8M para realização do ensaio de tração. (A) $56,0 \mathrm{~mm}$; (G) 50,0 \pm 0,1 $\mathrm{mm}$; (D) $12,5 \pm 0,2 \mathrm{~mm}$ e (R)=10,0 mm.

Os ensaios de tração foram executados em corpos de prova de tração transversal, onde o eixo longitudinal do corpo de prova é perpendicular ao eixo longitudinal do cordão de solda em temperatura ambiente e com taxa de deformação de 1,0 $\mathrm{mm} / \mathrm{min}$.

\subsection{Amostras para Ensaio de Microdureza Vickers}

Para as medições de microdureza foi utilizado um microdurômetro preparado para medir microdureza Vickers com seleção de carga para $300 \mathrm{gf}$ e tempo de permanência de 15 segundos. Neste ensaio foi utilizado um penetrador piramidal de diamante com base quadrada e ângulo de $136^{\circ}$, e distanciamento entre indentações de no mínimo 2,5 vezes a diagonal do prisma formado pela penetração do penetrador seguindo orientação da norma ASTM E384. A Figura 2 apresenta a

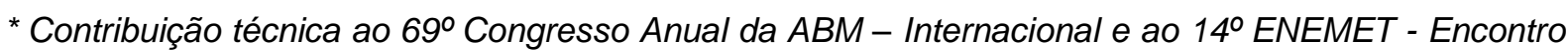
Nacional de Estudantes de Engenharia Metalúrgica, de Materiais e de Minas, 21 a 25 de julho de 2014, São Paulo, SP, Brasil. 


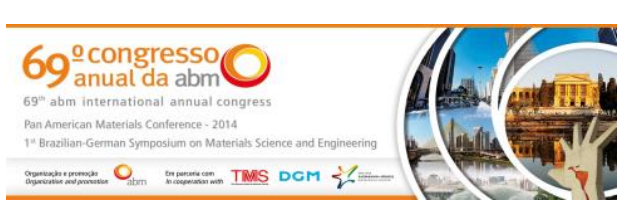

recomendação mínima da distância entre indentações sugerida pela Norma ASTM E384. [5]

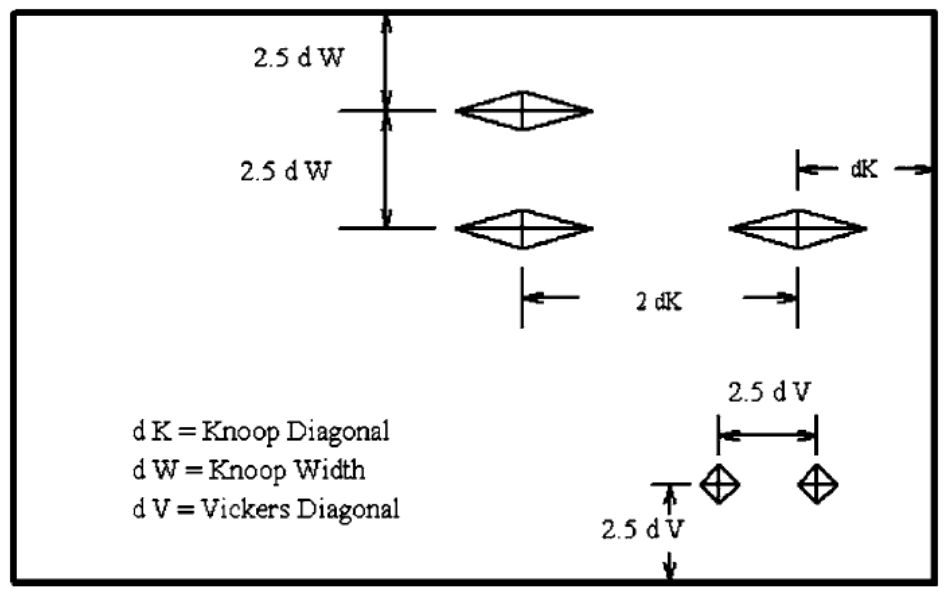

Figura 2- Espaçamento mínimo entre identações segundo a Norma ASTM E384.

\subsection{Ensaio de Impacto Charpy}

O ensaio de Impacto Charpy foi realizado em uma máquina montada com martelo de impacto de 500J e sistema de aquisição de dados por software computacional.

Todos os ensaios foram realizados em temperatura ambiente e de cada junta soldada foram retirados três corpos de prova com dimensões segundo a norma ASTM E-23.

Os entalhes dos corpos de prova foram usinados em uma brochadeira com ferramenta normalizada para abertura de entalhe $\mathrm{V}$.

\section{RESULTADOS E DISCUSSÃO}

Para nomenclatura das microestruturas identificadas foi utilizado como referência a classificação do Instituto Internacional de Soldagem (IIW).

\subsection{Micrografia do Metal de Base}

Na Figura 3 foi observado a ocorrência do fenômeno conhecido como bandeamento. Este fenômeno representa uma forte influência para as microestruturas, mas principalmente para as propriedades mecânicas, pois os materiais podem apresentar um comportamento de caráter anisotrópico com variações de propriedades mecânicas de acordo com a posição de solicitação. [6-8]

\footnotetext{
* Contribuição técnica ao $69^{\circ}$ Congresso Anual da ABM - Internacional e ao 14ํㅡㄹ ENEMET - Encontro Nacional de Estudantes de Engenharia Metalúrgica, de Materiais e de Minas, 21 a 25 de julho de 2014, São Paulo, SP, Brasil.
} 

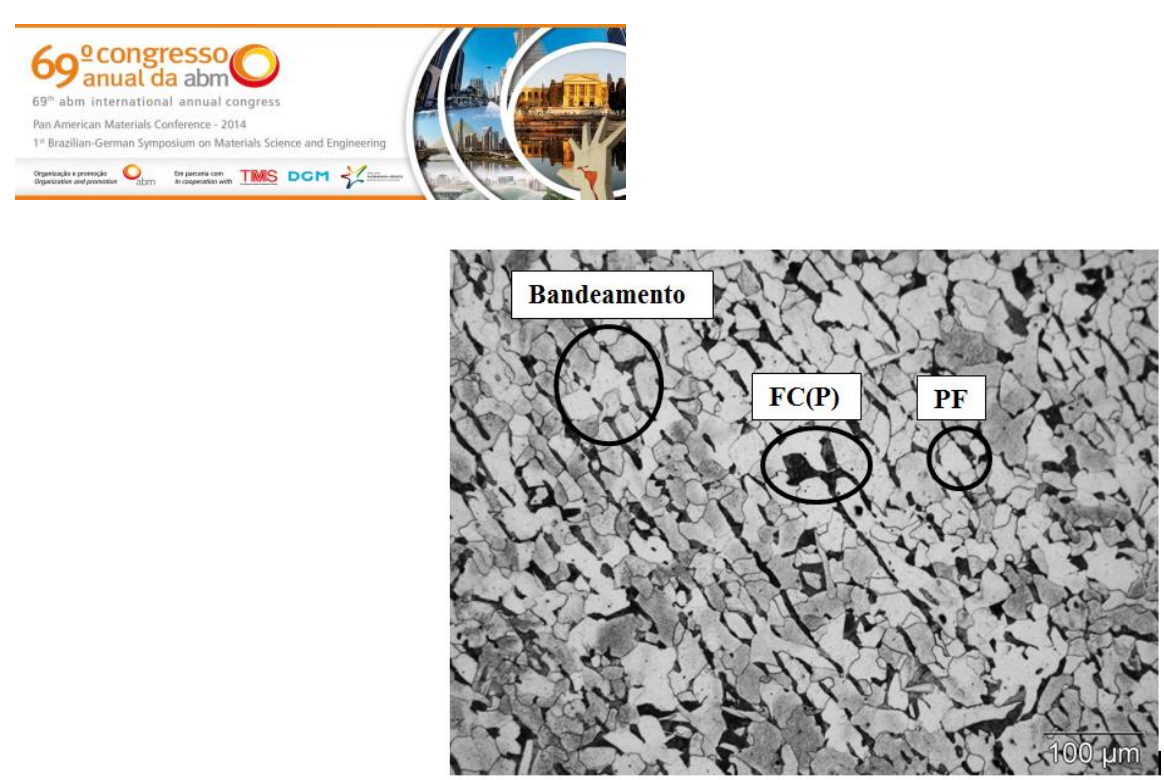

Figura 3 - Micrografia com aumento de 200X do aço ASTM A-36 utilizado como metal de base para confecção da junta soldada. Ataque Nital $2 \%$. Perlita (FC(P)) e Ferrita primária (PF).

\subsection{Micrografia da Zona Termicamente Afetada}

A Figura 4 mostra a região da zona termicamente afetada da junta soldada que utilizou o processo FCAW. Nesta região foram encontradas as microestruturas: Ferrira Acicular (AF), Ferrita com segunda fase não-alinhada (FS(NA)), Ferrita com segunda fase alinhada ( $F S(A))$ e Ferrita de contorno de grão (PF(G)).

A Figura 5 mostra a região da zona termicamente afetada da junta soldada que utilizou o processo SMAW. Nesta região foram encontrados os mesmos grãos que na região termicamente afetada da junta soldada com processo FCAW, mas com tamanhos de grãos maiores.

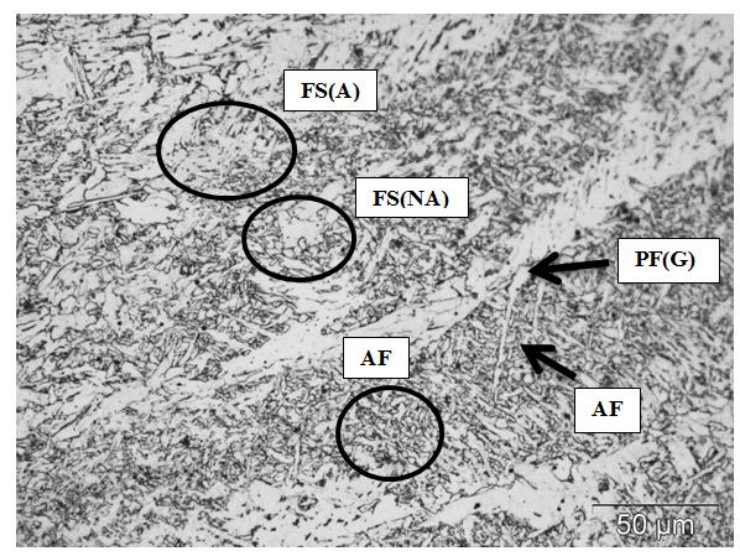

Figura 4. Zona termicamente afetada obtida pelo processo FCAW com aumento de 500X.

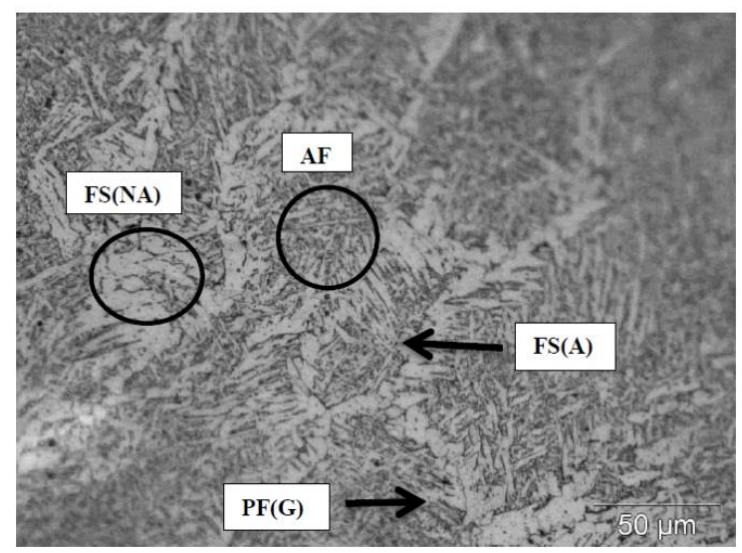

Figura 5. Zona termicamente afetada obtida pelo processo SMAW com aumento de 500X.

\footnotetext{
* Contribuição técnica ao $69^{\circ}$ Congresso Anual da ABM - Internacional e ao 14ํㅡㄹ ENEMET - Encontro Nacional de Estudantes de Engenharia Metalúrgica, de Materiais e de Minas, 21 a 25 de julho de 2014, São Paulo, SP, Brasil.
} 


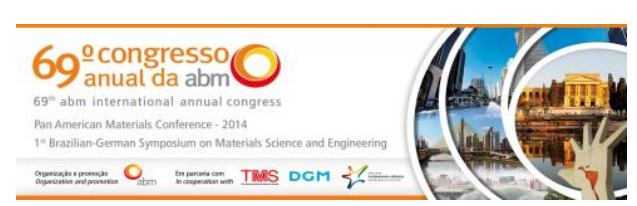

\subsection{Microdureza Vickers}

No ensaio de microdureza foram encontrado valores de dureza mais baixos no metal de base por ser constituído por uma matriz de ferrita e perlita. Na medida em que o perfil avançava, foi percebido um aumenta na dureza devido o surgimento de diferentes fases até atingir seu valor máximo na Zona Fundida. Este comportamento pode ser justificado pela presença de ferrita acicular na zona termicamente afetada e na zona fundida.

O valor de dureza da junta soldada que utilizou o processo de soldagem FCAW ficou no intervalo de $223 \mathrm{HV}$ a $250 \mathrm{HV}$, já a junta que utilizou o processo SMAW ficou no intervalo de $187 \mathrm{HV}$ a $210 \mathrm{HV}$.

Estes valores de dureza são reflexo das fases e dos tamanhos de grãos formados na zona termicamente afetada das juntas soldadas.

\subsection{Ensaio de Tração}

A Tabela 2 apresenta os resultados obtidos através da média dos três corpos de prova utilizados no ensaio de tração para cada junta soldada.

Tabela 2 - Médias dos resultados obtido no ensaio de tração.

\begin{tabular}{cccc}
\hline Junta Soldada & $\begin{array}{c}\text { Limite de } \\
\text { Resistência } \\
(\mathbf{M P a})\end{array}$ & $\begin{array}{c}\text { Limite de } \\
\text { Escoamento } \\
(\mathbf{M P a})\end{array}$ & $\begin{array}{c}\text { Alongamento } \\
(\mathbf{m m})\end{array}$ \\
\hline FCAW & $403,10 \pm 6,21$ & $260,43 \pm 21,57$ & $21,42 \pm 0,25$ \\
SMAW & $404,49 \pm 6,38$ & $252,43 \pm 17,77$ & $24,79 \pm 2,35$
\end{tabular}

Os resultados apresentados na Tabela 2 foram considerados todos válidos já que todos os corpos de prova romperam fora da região da solda e confirmam as exigências mínimas especificadas pela norma ASTM A-36.

\subsection{Ensaio de Impacto Charpy}

O resultado da média dos três corpos de prova rompidos no ensaio de impacto Charpy de cada junta soldada está apresentado na tabela 3.

Tabela 3 - Médias dos resultados obtido no ensaio de Impacto Charpy.

$\begin{array}{ccc}\begin{array}{c}\text { Junta } \\ \text { Soldada }\end{array} & \begin{array}{c}\text { Energia de } \\ \text { Impacto } \\ (\mathbf{J} / \mathbf{c m} 2)\end{array} & \begin{array}{c}\text { Energia } \\ \text { (J) }\end{array} \\ \text { FCAW } & 289,6 \pm 29,69 & 231,66 \pm 23,77 \\ \text { SMAW } & 303,56 \pm 54,21 & 242,8 \pm 43,36\end{array}$

\footnotetext{
* Contribuição técnica ao $69^{\circ}$ Congresso Anual da ABM - Internacional e ao 14ํㅡㄹ ENEMET - Encontro Nacional de Estudantes de Engenharia Metalúrgica, de Materiais e de Minas, 21 a 25 de julho de 2014, São Paulo, SP, Brasil.
} 


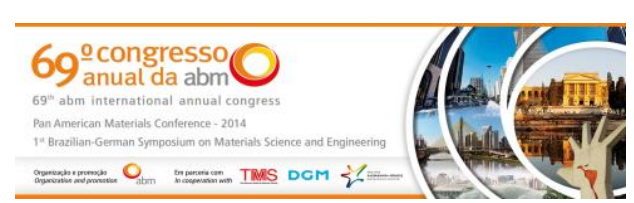

Devido os altos valores de desvio padrão não foi possível afirmar qual das condição possuía maior valor de energia absorvida.

\section{CONCLUSÃO}

$\mathrm{Na}$ zona termicamente afetada foram encontradas ferrita de contorno de grão $(P F(G))$, Ferrira Acicular (AF), ferrita com segunda fase alinhada (FS(A)) e Ferrita com segunda fase não-alinhada ( $F S(A))$ sendo que nas amostras que utilizaram o processo SMAW o tamanho destes microconstituintes eram maiores, possivelmente devido aos ciclos térmicos gerados pela baixa velocidade de soldagem quando comparado com o processo FCAW. Os tamanhos destes grãos tiveram forte influência no comportamento mecânico das juntas soldadas.

\section{Agradecimentos}

PRH-PB03;

À empresa Tomé Engenharia; PPGEM.

\section{REFERÊNCIAS}

1 ASTM A36 / 36M. Standard Specification for Carbon Structural Steel: Annual Book of ASTM Standards. USA: [s.n.]. 2008. 4p.

2 Bohler. Arame Tubular, Catálogo de Soldagem. Disponível em: http://www.bohlersoldabrasil.com.br. Acesso em: Jan. 2013.

3 ESAB. OK - Eletrodos Revestidos, Catálogo de Soldagem. Disponível em: http://www.esab.com.br. Acesso em: ago.2012.

4 ASTM E8 / 8M. Standard Test Methods for Tension Testing of Metallic Materials [Metric]: Annual Book of ASTM Standards. USA: [s.n.]. , 2011. 28p.

5 ASTM A 384. Standard Test Method for Microindentation Hardness of Materials: Annual Book of ASTM Standards. USA: [s.n.]. 2011. 43p.

6 Krauss G. Solidification, Segregation, and Banding in Carbon and Alloy Steels. Metallurgical and Materials Transactions, 2003; 34B: 787 - 788.

7 Albuquerque SF, Maciel TM, Santos MA, Bracarense AQ. Avaliação da Microestrura e Propriedades Mecânicas de Metais de Solda Obtidos por Processos de Soldagem Manual e Automatizado utilizado na Soldagem de Aço API 5L X80, Soldag. Insp. São Paulo, Vol.16, No. 4, p.322-332, Out/Dez 2011.

8 Lessa CRL et al. Estudo da microestrutura formada no processo de soldagem por atrito em aço C-Mn com pino consumível, Universidade Federal do Rio Grande do Sul, v.16, n. 1, p.002-011, set. 2012.

\footnotetext{
* Contribuição técnica ao $69^{\circ}$ Congresso Anual da ABM - Internacional e ao 14ํㅡㄹ ENEMET - Encontro Nacional de Estudantes de Engenharia Metalúrgica, de Materiais e de Minas, 21 a 25 de julho de 2014, São Paulo, SP, Brasil.
} 